\title{
Antiparkinsonian Agent
}

National Cancer Institute

\section{Source}

National Cancer Institute. Antiparkinsonian Agent. NCI Thesaurus. Code C38149.

Any agent that is used in the treatment of Parkinson's disease. Antiparkinsonian agents act by restoring the striatal balance between dopaminergic and cholinerg ic neurotransmission. 